\title{
Comparison of 27-gauge versus 25-gauge vitrectomy results in patients with epiretinal membrane: 6-month follow-up
}

\author{
Wojciech Lubiński (ib - Wojciech Gosławski • Karolina Podborączyńska-Jodko • \\ Maciej Mularczyk $\cdot$ Michał Post
}

Received: 3 December 2018/ Accepted: 16 December 2019/Published online: 19 January 2020

(C) The Author(s) 2020

\begin{abstract}
Purpose To compare the $27 \mathrm{G}$ versus $25 \mathrm{G}$ vitrectomy in patients with epiretinal membrane (ERM).

Patients and methods Sixty pseudophakic eyes of 60 consecutive patients treated by pars plana vitrectomy (PPV) using 27G (30 eyes) or 25G (30 eyes) were prospectively evaluated including eye's inflammation, surgery time, ERM + ILM removal time and complications. Additionally, 1, 3, 7, 14, 30, 90 and 180 days after PPV, the following were estimated: intraocular pressure (IOP), sclerotomy wound closure time, distance best corrected visual acuity (DBCVA), foveal macular thickness (FMT) and surgically induced astigmatism (SIA).

Results The eye's inflammation resolved within 30 days after surgery in both groups. The surgery and ERM + ILM times were longer in the $27 \mathrm{G}$ group $(p \leq 0.02)$. The most common postoperative complication was hypotony in both groups, more common in
\end{abstract}

W. Lubiński · W. Gosławski ·

K. Podborączyńska-Jodko · M. Post

2nd Department of Ophthalmology, Pomeranian Medical

University, Szczecin, Poland

\section{W. Lubiński $(\bowtie)$}

II Klinika Okulistyki, Pomorski Uniwersytet Medyczny, ul. Powstańców Wlkp. 72, 70-111 Szczecin, Poland e-mail: lubinski@pro.onet.pl

M. Mularczyk

Chair and Department of Human and Clinical Anatomy,

Pomeranian Medical University, Szczecin, Poland
$25 \mathrm{G}$ group ( $23.3 \%$ vs. $10 \%$ of eyes). In $27 \mathrm{G}$ group, the mean IOP prior to 180 days postoperatively was higher $(p<0.05)$ and the sclerotomy wound closure time was shorter $(p<0.001)$. Mean DBCVA values (7, 14, 30 days after surgery) were significantly better in $27 \mathrm{G}$ group $(p<0.001)$. The mean FMT values were similarly and significantly reduced in both groups 1 day postoperatively $(p<0.05)$ as compared to preoperative values and then stabilized during follow-up. Mean SIA was lower in 27G group 30, 90 and 180 days after surgery $(p<0.001)$.

Conclusion The use of $27 \mathrm{G}$ PPV in patients with ERM significantly reduced sclerotomy wound closure time and surgically induced astigmatism, better stabilized intraocular pressure and allowed to achieve faster visual acuity improvement, as compared to $25 \mathrm{G}$ PPV.

Keywords Epiretinal membrane $\cdot 27$-gauge $\cdot$ 25-gauge - Pars plana vitrectomy · Visual acuity · Surgery time $\cdot$ Self-sealing sclerotomy time . Intraocular pressure $\cdot$ Complications

\section{Introduction}

Transconjunctival microincision vitrectomy with $25 \mathrm{G} / 23 \mathrm{G}(0.5 / 0.7 \mathrm{~mm}$ in diameter, respectively) instrumentation resulted in a low rate of intraoperative and postoperative complications, such as hypotony 
and endophthalmitis [1, 2]. Nowadays, progress in vitrectomy devices, stiffness of instruments and light sources have led to the development of $27 \mathrm{G}(0.4 \mathrm{~mm}$ in diameter) transconjunctival sutureless vitrectomy [3]. The use of $27 \mathrm{G} \mathrm{PPV}$ in the treatment for posterior segment diseases [4-6] becomes more and more common, including the surgical treatment of some macular diseases, such as epiretinal membranes. There are no conclusive study results in the literature available that would indicate superiority of $27 \mathrm{G}$ vitrectomy over $25 \mathrm{G}$ vitrectomy in the treatment for epiretinal membranes [7-10]. That is why we decided to conduct this prospective study on 60 eyes with idiopathic epiretinal membranes undergoing $27 \mathrm{G}$ or $25 \mathrm{G}$ vitrectomy and compare postoperative outcomes.

\section{Patients and methods}

A prospective, comparative study was conducted, involving pseudophakic 60 eyes of 60 patients with ERM treated with 27G PPV (30 eyes) or 25G PPV (30 eyes) at 2nd Department of Ophthalmology, Pomeranian Medical University in the year 2017. This study adhered to principles of the Declaration of Helsinki and was approved by the local ethics committee. The written informed consent was obtained from all patients participating in the study. For comparison purposes, the surgical methodology, exclusion criteria, parameters analyzed before and after PPV were similar to those described by Mitsui et al. [7]. Patients with prior sclera buckling procedure, PPV, high myopia $>$ than -8.00 diopters, diabetes or cataract were excluded from the study. All surgeries were performed by one right-handed surgeon (WL) using the Alcon Constellation Vision System (Alcon Laboratories, Fort Worth, TX, USA) through three-port trocar cannula system. The surgical parameters for 25 GPPV were as follows: cutting rate 5000 cuts per minute (cpm), linear aspiration 0-650 mmHg, for $27 \mathrm{GPPV}$ : cutting rate $7500 \mathrm{cpm}$, linear aspiration $0-650 \mathrm{mmHg}$. In both types of vitrectomy, IOP was controlled by a system and equal to $20 \mathrm{mmHg}$. For posterior visualization, surgical microscope, model Hi-R 900 (MÖLLER-WEDEL GmbH \& Co. KG, Wedel, Germany), was used. The ERM and ILM were double stained using trypan blue dye.

The eyes with ERM were assigned for $25 \mathrm{G}$ or $27 \mathrm{G}$ surgery in alternating manner. The conjunctiva was moved from the planned sclerotomy site, and then the trocar was placed approximately $3.5 \mathrm{~mm}$ posteriorly to the limbus at $30^{\circ}$ angle to the scleral surface in three quadrants: superotemporal, inferotemporal and superonasal. Insertion angle of the trocar was measured by our custom-made protractor (Fig. 1).

At the end of the PPV, the cannulas were removed and gentle massage of the sclerotomy site using a cotton-tipped applicator was performed.

Additionally, 1, 3, 7, 14, 30, 90 and 180 days after PPV, the following outcomes were estimated: inflammation of anterior and posterior segment of the eye (slit lamp, indirect ophthalmoscopy), intraocular pressure (IOP, Goldmann applanation tonometer), presence of sclerotomy gaps (AS-OCT CASIA 2, Tomey, Japan), distance best corrected visual acuity (DBCVA-logMAR), central (foveal) macular thickness (FMT-SD-OCT, Cirrus HD-OCT, Carl Zeiss Meditec, Dublin, CA, USA) and surgically induced astigmatism (SIA). The assessor was masked to the gauge of vitrectomy which the patient had. Hypotony was defined as an IOP $<7 \mathrm{mmHg}$. The duration of vitrectomy was defined as time of vitreous cutter operation; the surgery time for peeling was the duration of removal of ERM and inner limiting membrane (ILM) using vitreous forceps. The

Fig. 1 Insertion angle $\left(30^{\circ}\right)$ of the trocar was measured by our custom-made protractor
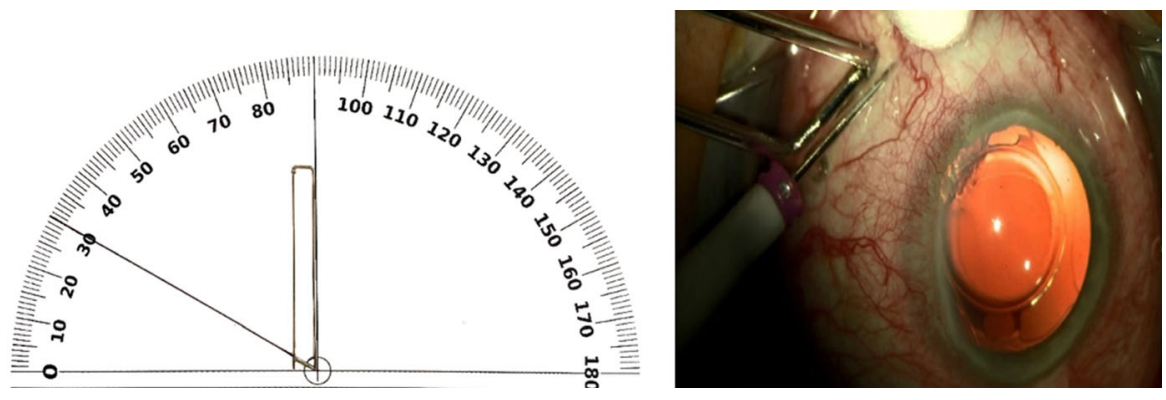
Table 1 Characteristics of patients from 27G (30 eyes) and 25G (30 eyes) PPV groups as mean \pm standard deviation of age and axial length of eye, and preoperative parameters: FTM, logMAR DBCVA and IOP

\begin{tabular}{lccc}
\hline Parameter & 27G (mean $\pm \mathrm{SD})$ & 25G (mean \pm SD) & $p$ value* \\
\hline Age & $65.40 \pm 4.29$ & $67.50 \pm 4.18$ & 0.052 \\
Axial length $(\mathrm{mm})$ & $23.28 \pm 1.09$ & $23.44 \pm 0.94$ & 0.796 \\
FMT $(\mu \mathrm{m})$ & $477.47 \pm 39.39$ & $469.43 \pm 38.87$ & 0.391 \\
log MAR DBCVA & $0.56 \pm 0.08$ & $0.58 \pm 0.08$ & 0.308 \\
IOP $(\mathrm{mm} \mathrm{Hg})$ & $14.03 \pm 1.30$ & $14.07 \pm 1.44$ & 0.947 \\
\hline
\end{tabular}

FMT foveal (central) macular thickness, IOP intraocular pressure, DBCVA distant best corrected visual acuity, logMAR logarithm of the minimal angle of resolution

*U Mann-Whitney test

surgically induced astigmatism (SIA) was measured using methodology described by Holladay et al. [11]. Wound closure was defined as the closure of all three sclerotomies in operated eye.

Statistical analysis

All statistical analyses of results obtained from 27G/ $25 \mathrm{G}$ groups were performed by means of Student's $t$, Mann-Whitney $U$ or Friedman's ANOVA tests. $p$ values of $<0.05$ were defined as statistically significant.

\section{Results}

The characteristics of patients included in the study are shown in Table 1.

There were no significant differences concerning number of eyes, age, axial length, FMT, DBCVA$\log$ MAR and IOP in 27G and 25G PPV groups. All patients from both groups were pseudophakic. The ERM and ILM were removed in all cases. Scleral or conjunctival sutures were not used. Fluid-gas exchange was not performed.
Inflammation of anterior and posterior segment of the eye

The inflammation (flare in the anterior segmentTyndall effect, and presence of cells in posterior segment determined by means of Volk lens) of the eye resolved in all patients from both groups within 30 days after the surgery.

\section{Surgery time}

In 27G PPV group, the mean surgery time was significantly longer in comparison with $25 \mathrm{G}$ PPV group $(12.2 \pm 0.9$ vs. $9.3 \pm 1.0 \mathrm{~min} ; p=0.001)$. The mean time necessary for ERM + ILM removal was slightly but significantly prolonged in $27 \mathrm{G}$ group $(8.2 \pm 0.7$ vs. $7.8 \pm 0.5 \mathrm{~min} ; p=0.025)$ (Table 2).

Scleral wound closure

The mean time for wound closure for all sclerotomies was statistically significantly shorter in $27 \mathrm{G}$ group as compared to $25 \mathrm{G}$ group $(14.1 \pm 6.2$ vs. $30.3 \pm 9.5$ days) (Figs. 2, 3).

Table 2 Characteristics of intraoperative parameters and wound closure time in both groups as mean \pm standard deviation

\begin{tabular}{lccc}
\hline Parameter & 27G (mean $\pm \mathrm{SD})$ & 25G (mean $\pm \mathrm{SD})$ & $p$ value* \\
\hline Duration of vitrectomy use (min) & $12.2 \pm 0.9$ & $9.3 \pm 1.0$ & 0.001 \\
Duration of ERM-ILM peeling (min) & $8.2 \pm 0.7$ & $7.8 \pm 0.5$ & 0.025 \\
Wound closure time (days) & $14.1 \pm 6.2$ & $30.3 \pm 9.5$ & 0.001 \\
\hline
\end{tabular}

ERM epiretinal membrane, ILM inner limiting membrane *U Mann-Whitney test 
Fig. 2 Time required for wound closure for all sclerotomies in both groups. There was statistically significant difference between groups $(p=0.001)$

Fig. 3 Anterior segment OCT images of sclerotomies of patient's eyes from $27 \mathrm{G}$ group (left) and $25 \mathrm{G}$ group. In $27 \mathrm{G}$ group, complete wound closure was achieved within 14 days postoperatively, while in $25 \mathrm{G}$ group within 30 days after surgery

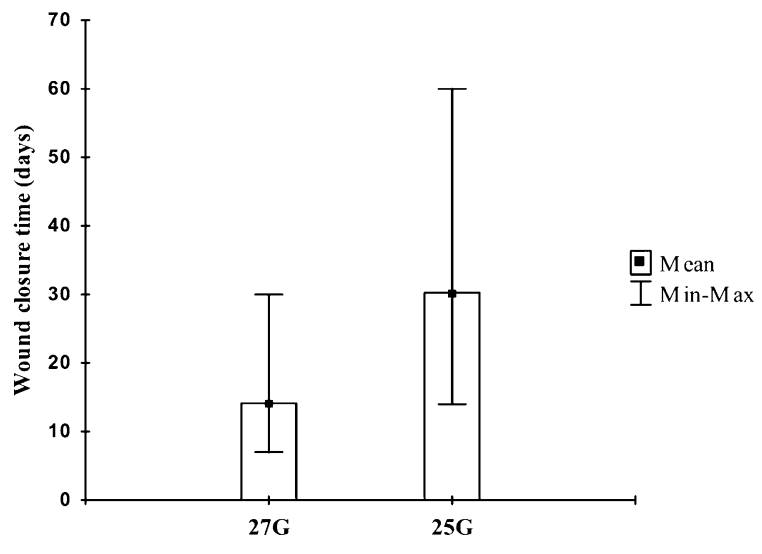

27 G PPV

Days

after

Days

after

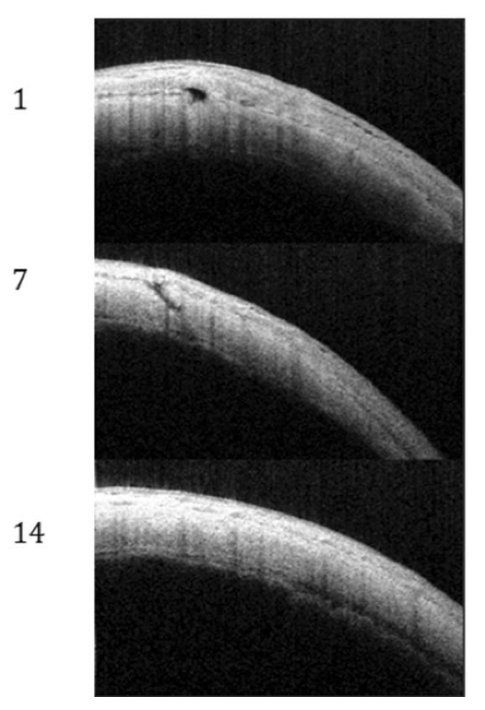

1

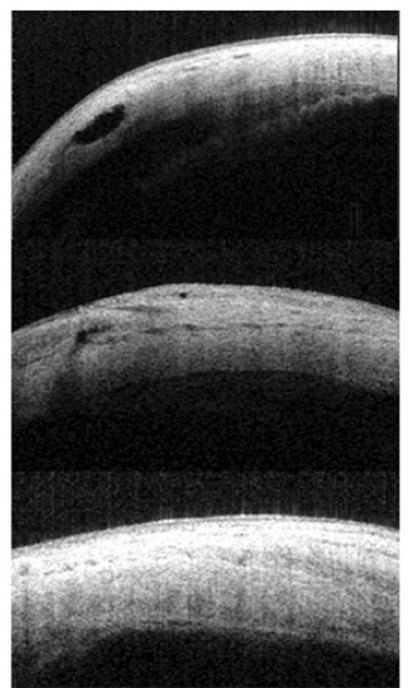

Visual acuity changes

Seven days after surgery, log MAR DBCVA was significantly better as compared to baseline values in $27 \mathrm{G}$ group $(p<0.05)$, but not in $25 \mathrm{G}$ group $(p>0.05)$. In subsequent inspections $(14,30,90$ and 180 days after surgery), log MAR DBCVA was significantly better in both groups $(p<0.05)$ (Table 3 , Fig. 4). There were significant differences in $\log -$ MAR DBCVA values between the both groups at 7-, 14- and 30-day follow-up visits with better VA for $27 \mathrm{G}$ group ( $p=0.001$ ) (Table 3, Fig. 4).
Surgically induced astigmatism

In $27 \mathrm{G}$ group, mean of SIA was significantly lower in comparison with mean SIA in $25 \mathrm{G}$ group $(p<0.05)$, Table 4.

Foveal macular thickness changes

In both groups, the mean FMT significantly decreased during follow-up period, as compared to baseline value $(p<0.05)$ but there were only insignificant differences in FMT between $27 \mathrm{G}$ and $25 \mathrm{G}$ groups in postoperative period analyzed (Table 5, Fig. 5). 
Table 3 Means \pm standard deviations of the log MAR DBCVA values in both groups during follow-up after vitrectomy

\begin{tabular}{llll}
\hline $\begin{array}{l}\text { logMAR } \\
\text { DBCVA }\end{array}$ & $\begin{array}{l}27 \mathrm{G} \\
(\mathrm{mean} \pm \mathrm{SD})\end{array}$ & $\begin{array}{l}25 \mathrm{G} \\
(\text { mean } \pm \mathrm{SD})\end{array}$ & $p$ value* \\
\hline Preoperative & $0.56 \pm 0.08$ & $0.58 \pm 0.08$ & 0.311 \\
1 day & $0.66 \pm 0.05$ & $0.68 \pm 0.08$ & 0.347 \\
3 days & $0.52 \pm 0.05$ & $0.54 \pm 0.08$ & 0.279 \\
7 days & $0.42 \pm 0.07$ & $0.52 \pm 0.07$ & 0.001 \\
14 days & $0.38 \pm 0.06$ & $0.48 \pm 0.07$ & 0.001 \\
30 days & $0.34 \pm 0.04$ & $0.42 \pm 0.07$ & 0.001 \\
90 days & $0.36 \pm 0.04$ & $0.38 \pm 0.07$ & 0.210 \\
180 days & $0.34 \pm 0.04$ & $0.36 \pm 0.07$ & 0.311 \\
\hline
\end{tabular}

*U Mann-Whitney test

Intraocular pressure changes

In $27 \mathrm{G}$ group, at 1,3 and 7 days after surgery, significant decrease in IOP was observed as compared to preoperative value $(p<0.05)$, but in $25 \mathrm{G}$ group the effect was noted also at 14 and 30 days $(p<0.05)$. During follow-up between 1 and 90 days after surgery, in $27 \mathrm{G}$ group mean IOP values were significantly higher than in $25 \mathrm{G}$ group $(p<0.002)$. No significant differences between groups were observed at 180 day postoperatively $(p<0.372)$ (Table 6 , Fig. 6).
Table 4 Means \pm standard deviations of SIA values in both groups during follow-up period after vitrectomy

\begin{tabular}{llll}
\hline SIA $(\mathrm{D})$ & $27 \mathrm{G}($ mean $\pm \mathrm{SD})$ & $25 \mathrm{G}($ mean $\pm \mathrm{SD})$ & $p$ value* \\
\hline 30 days & $0.42 \pm 0.06$ & $0.74 \pm 0.32$ & 0.001 \\
90 days & $0.32 \pm 0.03$ & $0.54 \pm 0.20$ & 0.001 \\
180 days & $0.25 \pm 0.09$ & $0.38 \pm 0.15$ & 0.001 \\
\hline
\end{tabular}

*U Mann-Whitney test

\section{Complications}

At the first day after surgery, in $27 \mathrm{G}$ group hypotony was observed less commonly ( $3 / 30$ of eyes $10 \%)$ than in $25 \mathrm{G}$ group $(7 / 30$ of eyes $23.3 \%)$. In both groups, retinal detachment in one eye was detected during follow-up period and additionally one macular hole in $27 \mathrm{G}$ group. In $27 \mathrm{G}$ group, the cause of retinal detachment was subretinal hemorrhage due to sudden increase in systemic blood pressure during the surgery. In $25 \mathrm{G}$ group, the cause of retinal detachment was peripheral tear formation 3 month after PPV. In both cases, successful additional PPV was performed. In $27 \mathrm{G}$ group, the cause of macular hole formation was remnants of inner limiting membrane. The removal of theses ILM remnants during next PPV resulted in the closure of macular hole and increase in VA. Choroidal detachment and endophthalmitis were not observed in any group.
Fig. 4 Mean values of $\log$ MAR DBCVA in time after vitrectomy. *Statistically significant difference as compared to the preoperative value (Friedman's ANOVA test $p<0.05$ )

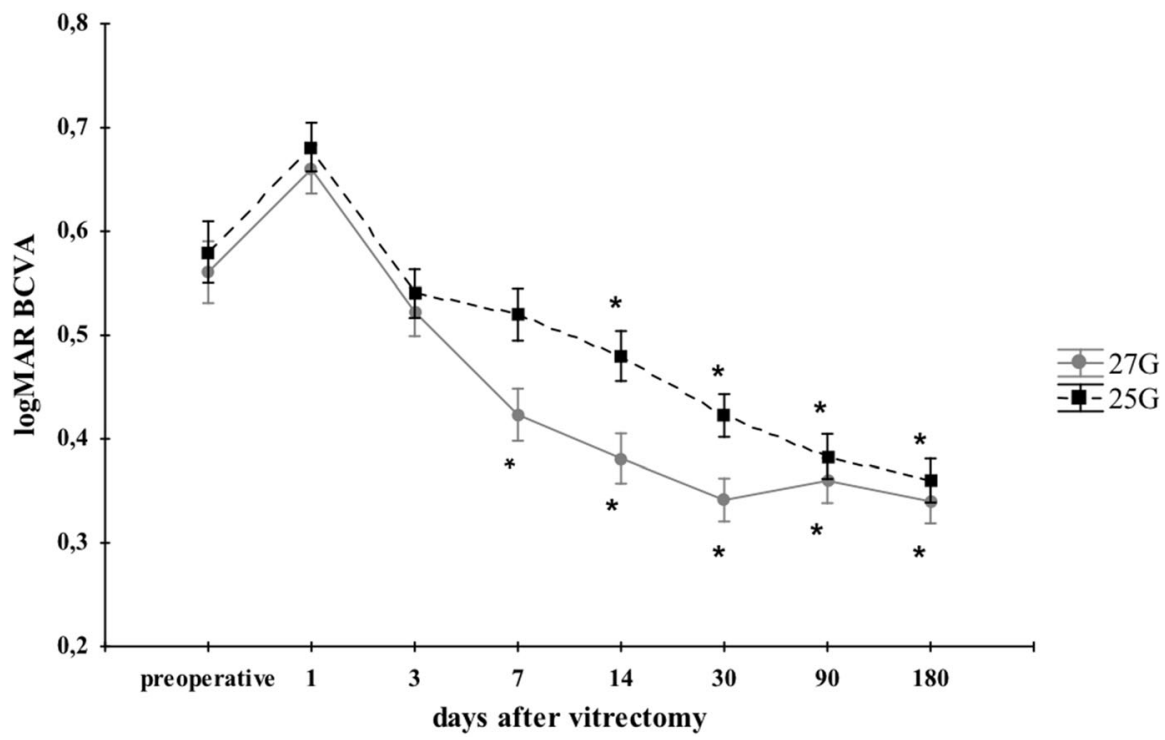


Table 5 Means \pm standard deviations of FMT values in both groups during follow-up after vitrectomy

\begin{tabular}{llll}
\hline FMT & $\begin{array}{l}27 \mathrm{G} \\
(\mathrm{mean} \pm \mathrm{SD})\end{array}$ & $\begin{array}{l}25 \mathrm{G} \\
(\text { mean } \pm \mathrm{SD})\end{array}$ & $p$ value* \\
\hline Preoperative & $477.47 \pm 39.39$ & $469.43 \pm 38.87$ & 0.391 \\
1 day & $404.07 \pm 32.86$ & $406.33 \pm 33.70$ & 0.912 \\
3 days & $423.07 \pm 28.42$ & $416.23 \pm 33.61$ & 0.318 \\
7 days & $392.23 \pm 25.04$ & $402.27 \pm 25.24$ & 0.104 \\
14 days & $394.07 \pm 24.57$ & $404.43 \pm 26.64$ & 0.126 \\
30 days & $390.23 \pm 23.31$ & $398.07 \pm 23.38$ & 0.183 \\
90 days & $392.13 \pm 23.14$ & $401.03 \pm 23.06$ & 0.089 \\
180 days & $396.10 \pm 22,32$ & $402.03 \pm 22,30$ & 0.209 \\
\hline
\end{tabular}

FMT foveal (central) macular thickness $* U$ Mann-Whitney test

\section{Discussion}

The results of the study presented suggest that in patients with ERM, 27G PPV provides more advantages as compared to 25G PPV, which was confirmed by other authors $[8,10]$. The mean time of wound closure for all sclerotomies was significantly shorter ( $\sim 16$ days) in $27 \mathrm{G}$ PPV group as compared to $25 \mathrm{G}$ PPV group. Analysis of logMAR DBCVA showed faster return of visual acuity (difference $\sim 1 \log$ MAR DBCVA) between 7 and 30 days after surgery in $27 \mathrm{G}$ PPV group. In $27 \mathrm{G}$ group, mean SIA was significantly lower (30 days $0.3 \mathrm{D}, 90$ days $0.2 \mathrm{D}$, 180 days $0.13 \mathrm{D}$ ) as compared to mean SIA in $25 \mathrm{G}$ group. During follow-up between 1 and 90 days postoperatively, in $27 \mathrm{G}$ group mean IOP values were significantly higher than in $25 \mathrm{G}$ group (by $\sim 1-4 \mathrm{~mm}$ $\mathrm{Hg}$ ). The most prominent difference was shown at the first day after surgery (mean IOP higher by $\sim 4 \mathrm{mmHg}$ in $27 \mathrm{G}$ group). At the first day after surgery, in $27 \mathrm{G}$ group hypotony was observed less commonly (three eyes) than in $25 \mathrm{G}$ group (seven eyes).

One of the disadvantages of $27 \mathrm{G}$ PPV is prolonged surgery time of ERM. In our series of patients, the surgery time for $27 \mathrm{G} \mathrm{PPV}$ group was significantly and approximately 3 min longer than that for $25 \mathrm{G}$ PPV. Prolonged surgery time for $27 \mathrm{G}$ PPV group was achieved also by Ito et al. ( $0.5 \mathrm{~min})$ [9], Mitsui et al. ( $\sim 4 \mathrm{~min})$ [7] and Naruse et al. ( $\sim 4 \mathrm{~min})$ [8]. The results obtained indicate that the reduced gauge of PPV instruments (lower infusion and aspiration rates) is responsible for longer time of surgery. Surgical trauma is a known cause of inflammation manifested by protein leakage and cell accumulation within the aqueous humor [12]. Prolonged time of surgery might be a cause for increase in flare in the anterior segment of the eye. The inflammation of the operated eyes resolved in all patients from both groups within 30 days after surgery. So the prolonged time in $27 \mathrm{G}$ group, as compared to $25 \mathrm{G}$ group, did not affect the duration of inflammation, which was also observed by other authors $[7,8]$.
Fig. 5 Mean values of FMT in time after vitrectomy. *Statistically significant difference as compared to preoperative value (Friedman's ANOVA test $p<0.05)$

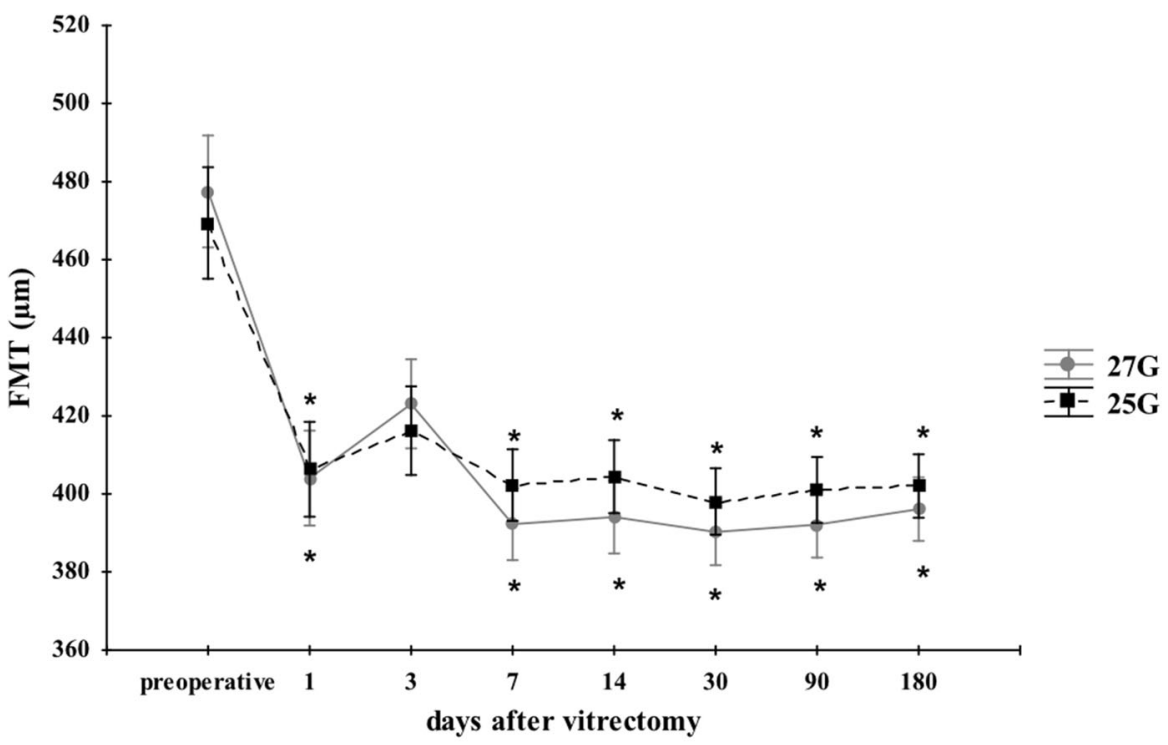


Table 6 Means \pm standard deviations of IOP values in both groups during follow-up after vitrectomy

\begin{tabular}{llrl}
\hline $\begin{array}{l}\text { Intraocular } \\
\text { pressure }\end{array}$ & $\begin{array}{l}\text { 27G } \\
(\text { mean } \pm \mathrm{SD})\end{array}$ & \multicolumn{1}{l}{$\begin{array}{l}25 \mathrm{G} \\
(\mathrm{mean} \pm \mathrm{SD})\end{array}$} & $p$ value* \\
\hline Preoperative & $14.03 \pm 1.3$ & $14.07 \pm 1.44$ & 0.956 \\
1 day & $11.10 \pm 1,06$ & $7.03 \pm 1.19$ & 0.001 \\
3 days & $12.20 \pm 1.32$ & $10.07 \pm 1.78$ & 0.001 \\
7 days & $12.00 \pm 1.26$ & $10.13 \pm 1.57$ & 0.001 \\
14 days & $13.07 \pm 1.26$ & $11.07 \pm 1.26$ & 0.001 \\
30 days & $13.40 \pm 1.30$ & $12.07 \pm 1.11$ & 0.001 \\
90 days & $14.13 \pm 1.28$ & $13.07 \pm 1.14$ & 0.002 \\
180 days & $14.40 \pm 0.97$ & $14.13 \pm 1.17$ & 0.372
\end{tabular}

*U Mann-Whitney test

It is reasonable to expect that $27 \mathrm{G}$ sclerotomies would close faster than $25 \mathrm{G}$ sclerotomies, as it was proven in the study. The mean time for all scleral wound closure was significantly shorter in $27 \mathrm{G}$ group, suggesting faster wound healing. In our study, the trocar was placed at $30^{\circ}$ angle to the scleral surface. For the first time for this purpose, a custom-made protractor was used, permitting precisely performed oblique incisions. Such incisions made at precisely controlled angle contribute significantly to the prevention of wound leakage. The wound edges are pressed together and closed by intraocular pressure [1]. In $27 \mathrm{G}$ group, faster sclerotomies healing observed could have resulted in faster recovery of visual acuity, IOP and lower frequency of hypotony.
Our results suggest that the size and precise angle of incision play an important role in terms of sclerotomy closure.

Mitsui et al. [7] did not observe significantly shorter scleral wound closure time associated with $27 \mathrm{G}$ PPV. It is not surprising, because in that study trocar insertion angle was not precisely determined, so there might be some variations in the angle. In consequence, shorter scleral tunnel could be created with higher possibility of wound leakage and prolonged healing. It is difficult to compare our result with the ones obtained by Naruse et al. [8] and Nakashina et al. [10] because of different angle of trocar placement, use of air or gas exchange, phacovitrectomy performance and more than one operating surgeon involved.

Our study results show that $27 \mathrm{G}$ PPV group featured earlier recovery of visual acuity in comparison with 25G PPV group and indicate superiority of surgery with smaller instrument gauge. The data obtained were confirmed by other authors [8].

Surgically induced astigmatism (SIA) may affect recovery of visual acuity after vitrectomy. Changes in the cornea shape after PPV may induce SIA. The SIA was significantly lower after $23 \mathrm{G}$ and $25 \mathrm{G}$ PPV as compared with $20 \mathrm{G}$ vitrectomy [13, 14]. In our study, in $27 \mathrm{G}$ PPV group, significantly smaller SIA was detected during the postoperative follow-up, as compared to 25G PPV group. Lower SIA associated with the use of $27 \mathrm{G} \mathrm{PPV}$ as compared with the $25 \mathrm{G}$ system, albeit not significant, was also observed by Mitsui
Fig. 6 Mean values of IOP in time after vitrectomy. *Statistically significant difference as compared to the preoperative value (Friedman's ANOVA test $p<0.05$ )

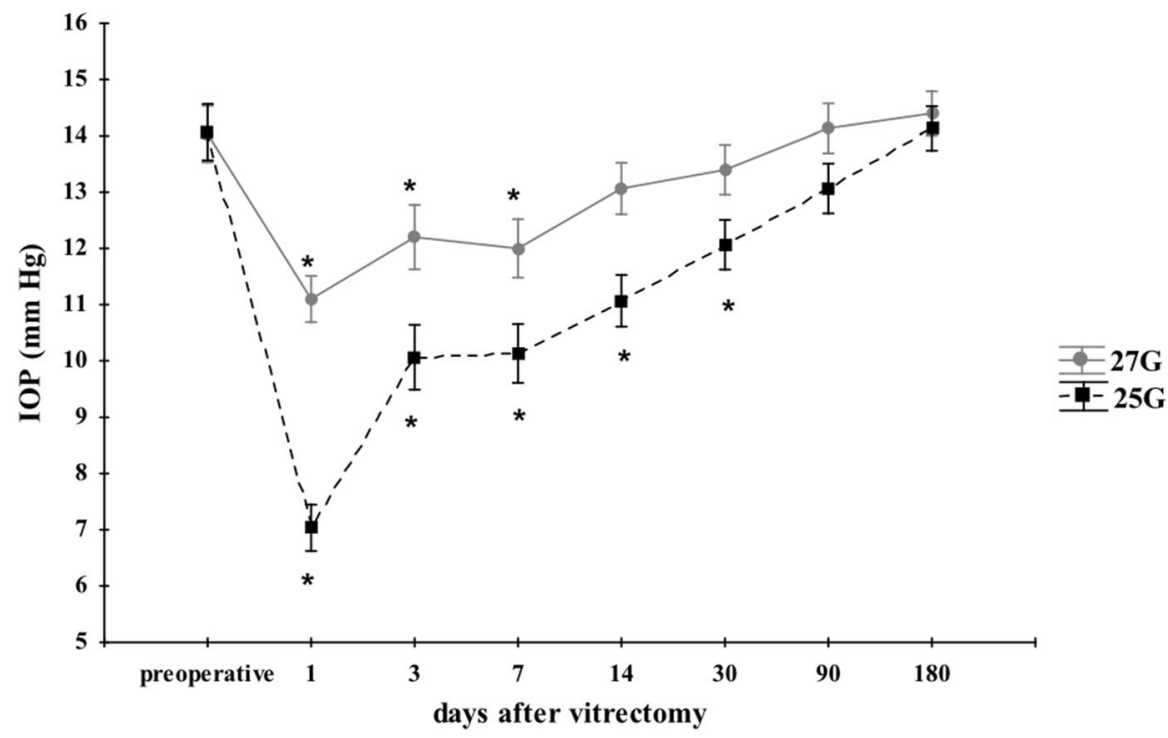


et al. [7]. This suggests that $27 \mathrm{G} P P V$ is less invasive than $25 \mathrm{G}$ PPV in terms of SIA.

In our study, the FMT was reduced significantly when compared to preoperative values, similarly to other studies [7,8] and there were no differences between $27 \mathrm{G}$ and $25 \mathrm{G}$ groups during six-month follow-up period. This relationship suggests that 1-mm-diameter reduction of sclerotomy in $27 \mathrm{G}$ $\mathrm{PPV}$, as compared to $25 \mathrm{GPPV}$, has no influence on the recovery of normal retinal structure in the macular region.

One of the important features which affects the recovery time of visual function is intraocular pressure level after vitrectomy. In our study, in $27 \mathrm{G}$ group IOP was significantly higher than in $25 \mathrm{G}$ group up to 90 days after the surgery and the most prominent difference was seen at first day postoperatively. This difference strongly suggests that smaller sclerotomy diameter with comparable length of scleral tunnel, as compared to $25 \mathrm{G} \mathrm{PPV}$, is responsible for faster sclerotomy closure and recovery of IOP to preoperative values. Similar relationships were noted by others [9]. One of the complications of microincision vitrectomy is hypotony due to evident or subclinical sclerotomy leakage. The oblique incision and gas tamponade are responsible for faster sclerotomy closure [15-17]. Also, smaller size of the wound has an impact on the closure of the sclerotomy and plays important role in hypotony prevention $[15,18]$. In our study, hypotony (arbitrary defined as IOP less than $7 \mathrm{mmHg}$ ) frequency was lower for $27 \mathrm{G}$ PPV group than in 25G PPV group and confirmed the abovementioned data. None of the patients had clinically significant hypotony in the form of hypotony maculopathy or choroidal detachment. In the study presented, we did not use gas tamponade; thus, small ( $0.4 \mathrm{~mm}$ size of sclerotomy) and precise, oblique incision was responsible for the reduction in hypotony incidence. In 27G PPV patients, reduced number or lack of hypotony was also observed by Mitsui [7], Naruse [8] and Ito [9].

In our study, the frequency of postoperative complications in 27/25G PPV groups was low and did not differ between the groups: vitreous hemorrhage and retinal detachment-one eye (1/30 eyes $3.3 \%)$ in both groups and additionally one case (1/30 eyes $3.3 \%$ ) of macular hole formation in $27 \mathrm{G}$ PPV group. The results obtained were comparable to those achieved by Naruse et al. [8]. Results from other studies [19, 20] indicate that smaller gauge PPV is associated with low risk of complications. Our study results are consistent with this conclusion.

Postoperative retinal breaks may occur uncommonly (2.6\%) [21] after PPV combining epiretinal membrane/inner limiting membrane peeling located centrally or extrafoveally as a full-thickness holes or pseudoholes [22]. It is suggested that weakening of the retinal glial structure as a consequence of Muller cell decapitation, opening of intraretinal cysts, direct mechanical trauma, dye toxicity and contraction of residual ILM may be responsible for hole formation. In our case in 27 GPPV group, residual ILM caused the macular hole formation and was treated successfully by next $27 \mathrm{G} \mathrm{PPV}$. There is no reason to associate this complication with small, 0.4-mm-diameter sclerotomies during $27 \mathrm{G}$ PPV. However, it cannot be excluded with certainty that this may be related to the tools used during surgery, i.e., $27 \mathrm{G}$ forceps.

The results of 6-month follow-up provided in this study indicate that the use of $27 \mathrm{G}$ PPV in patients with ERM significantly reduced sclerotomy wound closure time and surgically induced astigmatism, provided better stabilization of intraocular pressure and allowed faster achievement of visual acuity improvement as compared to 25G PPV. The above-mentioned advantages may determine the $27 \mathrm{G} \mathrm{PPV}$ as a technique of choice in the surgical treatment of ERM.

Further prospective studies with larger number of cases are necessary to verify those findings.

\section{Compliance with ethical standards}

Conflict of interest The authors declare no conflict of interest.

Ethical approval All procedures performed in studies involving human participants were in accordance with the ethical standards of the institutional and/or national research committee and with the 1964 Helsinki declaration and its later amendments or comparable ethical standards.

Open Access This article is licensed under a Creative Commons Attribution 4.0 International License, which permits use, sharing, adaptation, distribution and reproduction in any medium or format, as long as you give appropriate credit to the original author(s) and the source, provide a link to the Creative Commons licence, and indicate if changes were made. The images or other third party material in this article are included in the article's Creative Commons licence, unless indicated otherwise in a credit line to the material. If material is not included in the article's Creative Commons licence and your intended use is not permitted by statutory regulation or exceeds the permitted use, you will need to obtain permission directly 
from the copyright holder. To view a copy of this licence, visit http://creativecommons.org/licenses/by/4.0/.

\section{References}

1. Eckhardt C (2005) Transconjunctival sutureless $23 \mathrm{G}$ vitrectomy. Retina 25:208-211

2. Rizzo S, Genovesi-Ebert F, Murri S et al (2006) 25 G, sutureless vitrectomy and standard $20 \mathrm{G}$ paras plana vitrectomy in idiopathic epiretinal membrane surgery: a comparative pilot study. Graefes Arch ClinExpOphthalmol 244:472-479

3. Oshima Y, Wakabayashi T, Sato T, Ohji M, Tano Y (2010) A 27-gauge instrument system for transconjunctival sutureless microincision vitrectomy surgery. Ophthalmology 117:93-102

4. Ali Khan M, Shahlaee A, Toussaint B et al (2016) Outcomes of 27 gauge microincision vitrectomy surgery for posterior disease. Am J Ophthalmol 161:36-43

5. Rizzo S, Barca F, Caporossi T, Mariotti C (2015) Twentyseven-gauge vitrectomy for various vitreoretinal diseases. Retina 35:1273-1278

6. Yoneda K, Morikawa K, Oshima Y et al (2017) Surgical outcomes of 27-gauge vitrectomy for a consecutive series of 163 eyes with various vitreous diseases. Retina 37:2130-2137

7. Mitsui K, Kogo J, Takeda H et al (2016) Comparative study of 27 gauge versus 25 gauge vitrectomy for epiretinal membrane. Eye 30:538-544

8. Naruse S, Shimada H, Mori R (2017) 27-gauge and 25 gauge vitrectomy day surgery for idiopathic epiretinal membrane for idiopathic epiretinal membrane. BMC Ophthalmol 17:188

9. Ito M, Tanikawa A, Shimada Y, Horiguchi M (2016) Comparison of the operative times and intraocular pressure of sutureless vitrectomy with a 27-versus 25 -gauge system in eyes with epiretinal membrane. Fujita Med J 2(4):62-65

10. Takashina H, Watanabe A, Tsuneoka H (2017) Perioperative changes of the intraocular pressure during the treatment of epiretinal membrane by using 25- or 27-gauge vitrectomy without gas tamponade. Clin Ophthalmol 11:739-743

11. Holladay JT, Cravy TV, Koch DD (1992) Calculating the surgical induced refractive change following ocular surgery. J Cataract Refract Surg 18:429-443
12. Nishino M, Eguchi H, Iwata A et al (2009) Are topical steroids essential after an uneventful cataract surgery? J Med Invest 56:11-15

13. Okamoto F, Okamoto C, Sakata N et al (2007) Changes in corneal topography after 25-gauge transconjunctival sutureless vitrectomy versus after 20-gauge standard vitrectomy. Ophthalmology 114:2138-2141

14. Park DH, Shin JP, Kim SY (2009) Surgically induced astigmatism in combined phacoemulsification and vitrectomy; 23-G transconjuctival sutureless vitrectomy versus 20 gauge standard vitrectomy. Graefes Atrch Clin Exp Ophthalmol 247:1331-1337

15. Singh RP, Bando H, Brasil OF et al (2008) Evaluation of wound closure using different incision techniques with 23 -gauge and 25-gauge microincision vitrectomy systems. Retina 28(2):242-248

16. Shimada H, Nakashizuka H, Mori R et al (2006) 25-gauge scleral tunnel transconjunctival vitrectomy. Am J Ophthalmol 142(5):871-873

17. Hsu J, Chen E, Gupta OP et al (2008) Hypotony after 25 -gauge 25 -gauge vitrectomy using oblique versus direct cannula insertions in fluid- filled eyes. Retina 28(7):937-940

18. Chen D, Lian Y, Cui L, Lu F et al (2010) Sutureless vitrectomy incision architecture in the immediate postoperative period evaluated in vivo using optical coherence tomography. Ophthalmology 117(10):2003-2009

19. Sandali O, Sanharawi M, Lecuen N et al (2011) 25-, 23-, 20-gauge vitrectomy in epiretinal membrane surgery: a comparative study of 553 cases. Graefes Arch ClinExpOphthalmol 249:1811-1819

20. Haas A, Seidel G, Steinbrugger I, Maier R et al (2010) Twenty three-gauge and 20-gauge vitrectomy in epiretinal membrane surgery. Retina 30:112-116

21. Rush RB, Simunovic MP, Aragon AV, Ysasaga JE (2014) Postoperative macular hole formation after vitrectomy with internal limiting membrane peeling for the treatment of epiretinal membrane. Retina 34:890-896

22. Tachi N, Hashimoto Y, Kondo M et al (1997) Vitreous surgery for macular hole followed membrane peeling. Nihon Ganka Gakkai Zasshi 101:692-697

Publisher's Note Springer Nature remains neutral with regard to jurisdictional claims in published maps and institutional affiliations. 